$\mathrm{DE}$

M E D I C I N A

T R O P I C A L

$\mathrm{DE}$

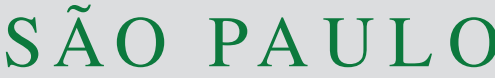

JOURNAL OF THE SÃO PAULO INSTITUTE OF TROPICAL MEDICINE

1 Universidade de São Paulo, Faculdade de Medicina, Hospital das Clínicas, Laboratório de Investigação Médica em Imunologia (LIM 48), São Paulo, São Paulo, Brazil

2Universidade de São Paulo, Faculdade de Medicina, Hospital das Clínicas, Laboratório de Investigação Médica em Micologia (LIM 53), São Paulo, São Paulo, Brazil

${ }^{3}$ Universidade de São Paulo, Instituto de Medicina Tropical de São Paulo, São Paulo, São Paulo, Brazil

${ }^{4}$ Universidade de São Paulo, Faculdade de Medicina, Departamento de Moléstias Infecciosas e Parasitárias, São Paulo, São Paulo, Brazil

Correspondence to: Felipe Delatorre Busser

Universidade de São Paulo, Faculdade de Medicina, Hospital das Clínicas, Laboratório de Investigação Médica em Imunologia (LIM 48), Av. Dr. Enéas de Carvalho Aguiar, 470, Prédio II, CEP 05403-907, São Paulo, SP, Brazil

Tel: +55 1130617049

E-mail: felipe_db89@ hotmail.com

Received: 7 August 2019

Accepted: 8 January 2020

\section{A Real Time PCR strategy for the detection and quantification of Candida albicans in human blood}

Felipe Delatorre Busser ${ }^{(1)}$, Vivian Caso Coelho', Claudia de Abreu Fonseca', Gilda Maria Barbaro Del Negro ${ }^{2,3}$, Maria Aparecida Shikanai-Yasuda ${ }^{1,4}$, Marta Heloisa Lopes ${ }^{1,4}$, Marcello Mihailenko Chaves Magri ${ }^{1}$, Vera Lucia Teixeira de Freitas ${ }^{(1)} 4$

\section{ABSTRACT}

Candidemia is a significant cause of bloodstream infections (BSI) in nosocomial settings. The identification of species can potentially improve the quality of care and decrease human mortality. Quantitative PCR (qPCR) was evaluated for Candida albicans detection using culture suspensions containing $C$. albicans, spiked human blood, the cloned qPCR target fragment (ITS2 region) and the results of these assays were compared. The assays showed a good detection limit: C. albicans DNA extracted from yeast (sensitivity $0.2 \mathrm{CFU} / \mu \mathrm{L}$ ), spiked human blood (sensitivity $10 \mathrm{CFU} / \mathrm{mL}$ ), and cloned fragment of ITS2 region (sensitivity 20 target copies/ $\mu \mathrm{L}$ ). The efficiency of ITS 2 fragment-qPCR ranged from 89.67 to 97.07 , and the linearity $\left(\mathrm{R}^{2}\right)$ of the standard curve ranged from 0.992 to 0.999 . The results showed that this ITS2-qPCR has a great potential as a molecular prototype model for the development of a test to be applied in clinical practice, greatly reducing the time of candidemia diagnosis, which is extremely important in this clinical setting.

KEYWORDS: Candida albicans. Candidemia. Detection. Invasive candidiasis. ITS2. Quantitative PCR.

\section{INTRODUCTION}

Candidemia is the fourth most common cause of bloodstream infections (BSI) in nosocomial settings, with up to $50 \%$ of episodes occurring in intensive care units (ICU) ${ }^{1}$. Patients with invasive candidiasis (IC), even receiving antifungal therapy, have a mortality rate of $40 \%^{2}$. Furthermore, candidemia increases the hospital length of stay and the total cost of medical care ${ }^{3}$. Girão et al. ${ }^{4}$ from Universidade de Sao Paulo (USP), evaluated nosocomial candidemia in an ICU at Hospital das Clinicas da Faculdade de Medicina da Universidade de Sao Paulo (HCFMUSP) for seven years, and they assessed 8.3 to 10.8 cases of BSI of 1,000 patients per day, and $5.6 \%$ of the cases were caused by Candida $s p$. The authors observed that $C$. albicans caused the majority of infections (40\%), followed by C. tropicalis (34\%), C. parapsilosis (18\%), C. krusei (3\%), and C. guilliermondii $(1 \%)^{4}$.

The diagnosis of Candida sp. BSI is challenging, and, in general, takes place in the later stages of the disease. The blood culture is currently the gold standard for the diagnosis of IC; however, it has low sensitivity, and takes 48-96 $\mathrm{h}$ to identify the species $^{5}$. The need of new tools for the diagnosis of candidemia is important due to the low sensitivity of blood culture, as only about $50 \%$ of all cases of candidemia are 
detected $^{6}$. Non-culture methods could successfully increase the sensitivity of the early diagnosis of $\mathrm{IC}^{7}$.

Quantitative PCR (qPCR) is considered a sensitive and accurate technique. The main advantage of this technique is the ability to generate quantitative data, in contrast to qualitative data generated by conventional PCR. Among the most promising targets for the diagnosis of invasive fungal infections by qPCR, the ITS (Internal Transcribed Spacer) region is part of the ribosomal RNA (rDNA) gene complex and has been used as a target in candidemia diagnosis by PCR. It is a non-coding region, and the genomic sequences are present in around 55 copies per haploid genome ${ }^{8}$.

The aim of this study is to evaluate an in-house qPCR specifically directed to $C$. albicans, applying a standard curve of a cloned fragment of the ITS2 region as a reference in future qPCR assays for the detection and quantification of $C$ albicans in human blood. This new assay should have a good detection limit, reproducibility and specificity.

\section{METHODS}

This study was approved by Comite de Etica em Pesquisa da Faculdade de Medicina da Universidade de Sao Paulo (Process $N^{\circ}$ 1.856.53). Blood samples from healthy participants were collected after the signature of an informed consent. The samples were stored at $4{ }^{\circ} \mathrm{C}$ until processing.

Yeast cells of $C$. albicans (ATCC 90028) were cultivated in Sabouraud agar plates $\left(37^{\circ} \mathrm{C} ; 24 \mathrm{~h}\right)$. They were added in a solution of Tris-HCl-EDTA (TE) and counted in a Neubauer chamber; subsequently, they were adjusted to a concentration of $10^{8}$ colony forming units per $\mathrm{mL}$ $(\mathrm{CFU} / \mathrm{mL})$.

Three sets of experiments were performed:

1) C. albicans suspension in a concentration of $10^{8} \mathrm{CFU} / \mathrm{mL}$

For DNA extraction, the pellet containing the yeasts was incubated at $37^{\circ} \mathrm{C}$ for two h in TE (Tris $\mathrm{HCl} 10 \mathrm{mM} \mathrm{pH}$ 8.0; EDTA $2 \mathrm{mM} \mathrm{pH} \mathrm{8.0)} \mathrm{and} 200 \mathrm{U}$ of Lyticase (Sigma-Aldrich, Missouri, USA). The remaining steps were performed by using the QIAamp ${ }^{\circledR}$ DNA Blood Mini Kit (QIAGEN Inc., Hilden, Germany), following the manufacturer's instructions. The sample was eluted in $100 \mu \mathrm{L}$ of an elution buffer (QIAGEN). DNA concentration was estimated by using a UV spectrophotometer (Nanodrop LITE, Thermo Fisher Scientific Corp., Wilmington, Delaware, USA). A ten-fold dilution series, from $10^{6}$ to $10^{-3} \mathrm{CFU} / \mu \mathrm{L}$ of the product of extraction, were submitted to amplification.

2) Spiked blood samples with $C$. albicans

C. albicans yeasts were added to non-infected human blood in a concentration of $10^{7} \mathrm{CFU} / \mathrm{mL}$, and immediately homogenized. The spiked blood was then used to produce a ten-fold dilution series $\left(10^{7}\right.$ to $\left.10^{\circ} \mathrm{CFU} / \mathrm{mL}\right)$. To other two blood aliquots of $1 \mathrm{~mL}$ each, 2 and 5 yeasts were added. An extraction control and blood without yeasts were processed along with the spiked curve dilutions

DNA extraction was performed by following the methodologies described previously ${ }^{9}$, with some modifications: each $1 \mathrm{~mL}$ of the spiked blood samples was initially treated with the blood lysis buffer $\left(\mathrm{NH}_{4} \mathrm{CL}\right.$ $155 \mathrm{mM} ; \mathrm{KHCO}_{3} 10 \mathrm{mM}$; EDTA $1 \mathrm{mM} \mathrm{pH}$ 7.4), followed by a centrifugation at $1,200 \mathrm{~g}$ for $15 \mathrm{~min}$; the pellet was incubated at $37{ }^{\circ} \mathrm{C}$ for $2 \mathrm{~h}$ with Nucleo Lysis Buffer (Tris HCL 10 mM pH 8.0; NaCL 0.4 mM; EDTA 2 mM pH 8.2), and $200 \mathrm{U}$ of Lyticase (Sigma-Aldrich, Missouri, USA) were added. The remaining steps were performed by using the QIAamp ${ }^{\circledR}$ DNA Blood Mini Kit, following the manufacturer's instructions.

\section{3) Cloning the fragment of the ITS2 region}

A 108-bpDNA fragment of ITS2 region was amplified from a C. albicans strain (Accession $\mathrm{N}^{\circ} \mathrm{KT}$ 876203.1), using the primers forward 5' - GGGTTTGCTTGAAAGACGGTA -3' and reverse 5'-TTGAAGATATACGTGGTGGACGTTA-3' in the $\mathrm{qPCR}^{10}$. Then, the $\mathrm{PCR}$ product was cloned into the plasmid vector pJET 1.2/blunt, using the CloneJET PCR Cloning Kit (Thermo Fisher Scientific Corp., Wilmington, Delaware, USA), following the manufacturer's instructions. The pJET 1.2/blunt of the ITS2 region linked to the plasmid was purified using the miniprep technique ${ }^{11}$. The DNA concentration was estimated by using a UV spectrophotometer (Nanodrop LITE, Thermo Fisher Scientific, Wilmington, Delaware, USA). In order to generate standard curves for the quantitative assays and to assess the amplification efficiency, a ten-fold dilution series of the pJET 1.2/blunt of the ITS2 region in the plasmid were prepared in $10 \mathrm{mM}$ Tris-EDTA buffer $\left(2 \times 10^{9}\right.$ to $2 \times 10^{\circ}$ copies $/ \mu \mathrm{L}$ ) and stored at $-80{ }^{\circ} \mathrm{C}$ until use. To minimize contamination, the preparation of the PJET 1.2/ blunt of the ITS2 region plasmid dilutions was carried out in a separate room of the laboratory.

The lowest concentration of C. albicans detected by qPCR was the detection limit, which was estimated by the dilution series, tested in three sets of experiments.

The qPCR assays were performed in $20 \mu \mathrm{L}$ of total volume containing $10 \mu \mathrm{L}$ of 2 X Power SYBR Green PCR Master Mix (Applied Biosystems, Carlsbad, California, USA), $0.2 \mathrm{mM}$ primers (region ITS-2) and $5 \mu \mathrm{L}$ of each DNA sample. A StepOne Plus Real Time PCR System (Applied Biosystems, Carlsbad, California, USA) was used. The cycling conditions consisted of an initial denaturation 
step at $95^{\circ} \mathrm{C}(5 \mathrm{~min})$, followed by 40 cycles at $95^{\circ} \mathrm{C}(30 \mathrm{~s})$, $58^{\circ} \mathrm{C}(30 \mathrm{~s})$, and $72{ }^{\circ} \mathrm{C}(30 \mathrm{~s})$, and a final dissociation step at $56-95^{\circ} \mathrm{C}$ with a heating rate of $0.3^{\circ} \mathrm{C} / \mathrm{s} .{ }^{10} \mathrm{To}$ estimate the equivalence between $\mathrm{CFU}$ and fentograms (fg) a previously reported methodology was followed ${ }^{12}$.

The assay reproducibility in detecting the cloned ITS2 fragment and spiked blood samples was evaluated in 15 independent assays: the first included ten assays with ten-fold dilution series of the cloned fragment $\left(2 \times 10^{9}\right.$ to $10^{\circ}$ copies/ $\mu \mathrm{L}$ ) and the second 5 assays with ten-fold dilution series of spiked blood $\left(10^{7}\right.$ to $\left.10^{0} \mathrm{CFU} / \mathrm{mL}\right)$. Both assays were performed in different days under the same conditions.

The qPCR specificity was evaluated by testing DNA samples from other Candida species, other fungi and bacteria (C. glabrata, C. parapsilosis, C. tropicalis, C. krusei, C. dubliniensis, Enterococcus faecalis, Pseudomonas aeruginosa, Staphylococcus aureus, Streptococcus agalactiae, Escherichia coli; Rhodotorula $s p$, Cryptococcus neoformans, Histoplasma capsulatum and Fusarium $s p$ ) in a DNA concentration of $5 \mathrm{ng} /$ reaction. As the positive control for these reactions, $C$. albicans DNA was used at concentrations of 0.05 and $5 \mathrm{ng} /$ reaction.

In addition, two negative controls (No Template Control - NTC) were included in each assay: one reagent control and one control to investigate contamination during the application of the standard curve samples.

The SPSS Statistics 17.0 software (SPSS Inc., Chicago, Illinois, USA) was used to determine the mean values and the standard deviations based on independent experiments for each set.

\section{RESULTS AND DISCUSSION}

For each of the two standard curves, five independent experiments were performed from a dilution series of spiked human blood, and ten independent experiments were performed from the cloned fragment of $C$. albicans, respectively.

Standard TS2 curves generated by ten-fold dilutions series of DNA from $2 \times 10^{9}$ to $2 \times 10^{\circ}$ copies $/ \mu \mathrm{L}$ concentrations showed a perfect agreement in all ten independent qPCR assays. The assays demonstrated high efficiency (between $89.03 \%$ to $101.46 \%$ ), and the other critical parameter evaluated, the linearity $\mathrm{R}^{2}$ was between $0.996 \pm 0.003$ (Table 1). The detection limit of the cloned ITS2 target indicated a mean $\mathrm{Ct}$ value of $32.97 \pm 0.99$, corresponding to 20 copies $/ \mu \mathrm{L}$ (Table 2 and Figure 1A). These results are similar to the other experiment in which the detection limit was 80 copies $/ \mathrm{mL}$ in serum or plasma samples from IC patients comparing the samples to a standard curve generated by diluted plasmids from $10^{8}$ to $10^{1}$ copies/reaction ${ }^{13}$.

The detection limit observed in qPCR assays with DNA samples of $C$. albicans from culture was $10^{-1} \mathrm{CFU} / \mu \mathrm{L}$, which corresponds approximately to $5 \mathrm{fg} /$ reaction (Table 2 and Figure 1B). This value is compatible with the results found in the limit dilution of the cloned sequence, i.e. 20 copies/reaction, which corresponds approximately to one-fifth of a single $\mathrm{CFU}$, considering approximately 110 copies of the sequence/CFU (diploid genome) $)^{8}$. Other authors who used $C$ albicans culture samples in qPCR observed similar results ${ }^{14,15}$.

Table 1 - qPCR performance to detect Candida albicans using cloned target sequence and spiked blood

\begin{tabular}{lcc}
\hline & Cloned target & Spiked blood \\
\hline Number of replicates & 10 & 5 \\
Slope $($ mean $\pm S D)$ & $-3.452 \pm 0.115$ & $-3.515 \pm 0.226$ \\
Linearity $\left(\mathrm{R}^{2}\right)$ & $0.996 \pm 0.003$ & $0.997 \pm 0.002$ \\
Efficiency $(\%)$ & $95.184 \pm 4.237$ & $97.056 \pm 4.088$ \\
\hline
\end{tabular}

Table 2 - Performance of qPCR in three sets of experiments

\begin{tabular}{|c|c|c|c|c|c|}
\hline \multicolumn{2}{|c|}{ Cloned Target* } & \multicolumn{2}{|c|}{ C albicans culture ${ }^{\star *}$} & \multicolumn{2}{|c|}{ Spiked Blood** } \\
\hline 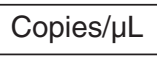 & Ct Mean \pm SD & $\mathrm{CFU} / \mu \mathrm{L}$ & Ct Mean \pm SD & CFU/mL of Blood & Ct Mean \pm SD \\
\hline $2 \times 10^{-1}$ & ND & & & $2 \times 10^{0}$ & ND \\
\hline $2 \times 10^{0}$ & ND & & ND & $5 \times 10^{0+*+x}$ & ND \\
\hline $2 \times 10^{1}$ & $32.98 \pm 1.00$ & $10^{-1}$ & $33.70 \pm 1.53$ & $10^{1}$ & $33.01 \pm 0.65$ \\
\hline $2 \times 10^{2}$ & $29.54 \pm 0.85$ & $10^{\circ}$ & $30.94 \pm 0.73$ & $10^{2}$ & $34.70 \pm 0.69$ \\
\hline $2 \times 10^{3}$ & $26.16 \pm 0.86$ & $10^{1}$ & $27.13 \pm 0.49$ & $10^{3}$ & $30.36 \pm 1.55$ \\
\hline $2 \times 10^{4}$ & $22.40 \pm 0.73$ & $10^{2}$ & $22.66 \pm 0.68$ & $10^{4}$ & $26.33 \pm 1.12$ \\
\hline $2 \times 10^{5}$ & $18.89 \pm 0.92$ & $10^{3}$ & $18.35 \pm 0.52$ & $10^{5}$ & $23.80 \pm 0.81$ \\
\hline $2 \times 10^{6}$ & $15.38 \pm 0.82$ & $10^{4}$ & $14.80 \pm 0.48$ & $10^{6}$ & $20.32 \pm 0.74$ \\
\hline $2 \times 10^{7}$ & $11.89 \pm 0.77$ & $10^{5}$ & $11.02 \pm 0.30$ & $10^{7}$ & $17.54 \pm 0.84$ \\
\hline
\end{tabular}

* mean of ten assays; ${ }^{* \star}$ mean of three assays; ${ }^{* \star}$ mean of five assays; ND - non detected 

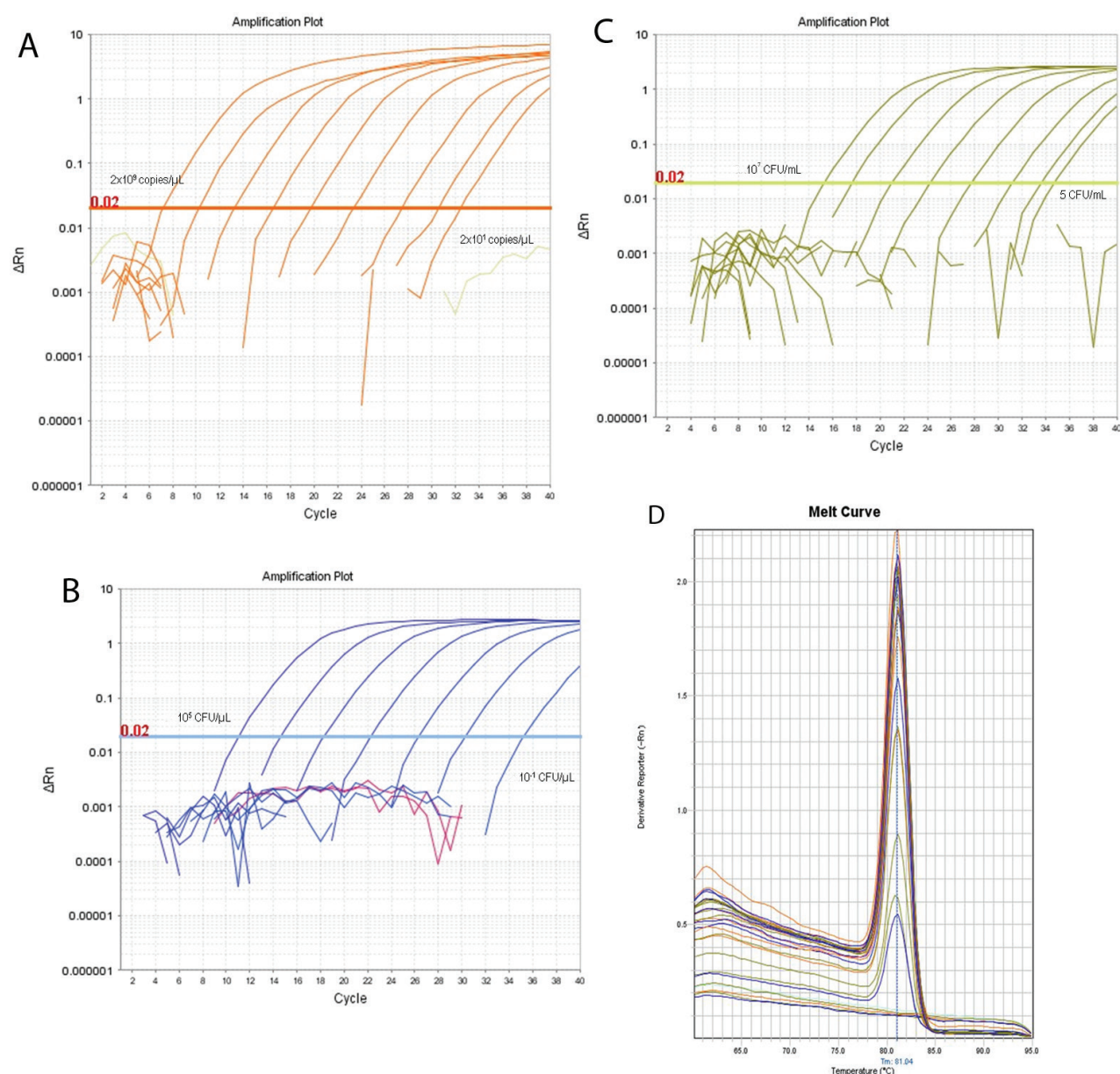

Figure 1 - Technical performance and detection range of the Candida albicans qPCR: A) Amplification curves of ten-fold dilutions of cloned targets ranging from $2 \times 10^{9}$ to $2 \times 10^{1}$ copies/ $\mu \mathrm{L}$; B) Amplification curves of ten-fold dilutions of cultures, ranging from $10^{5}$ to $10^{-1} \mathrm{CFU} / \mathrm{\mu L}$; C) Amplification curves of ten-fold dilutions of spiked blood, ranging from $10^{7}$ to $10^{1}$ and $5 \mathrm{CFU} / \mathrm{mL}$ of blood; D) Dissociation curves for the amplifications observed in A, B and C, where the same Melting temperature of $81.06 \pm 0.19^{\circ} \mathrm{C}$ was observed. The linearity $R^{2}$ value was 0.996 .

The present study allowed the detection of $10 \mathrm{CFU} / \mathrm{mL}$ of spiked blood samples in $100 \%$ of experiments and a detection of $5 \mathrm{CFU} / \mathrm{mL}$ in $50 \%$ of the same experiments. (Table 2 and Figure 1C). In the spiked blood samples, using similar methods, other researchers found $1 \mathrm{CFU} / \mathrm{mL}$ in $25 \%, 10 \mathrm{CFU} / \mathrm{mL}$ in $83 \%$, and $100 \mathrm{CFU} / \mathrm{mL}$ in $100 \%$ of the experiments ${ }^{16}$. Previous studies have also shown the limit of detection of $10 \mathrm{CFU} / \mathrm{mL}$ of blood ${ }^{17-19}$. One of them compared extraction methods as well, observing that the QIAamp ${ }^{\circledR}$ DNA Blood mini kit (QIAGEN) was more sensitive than the other methods in serum samples spiked with $C$. albicans ${ }^{17}$. The qPCR assays with spiked blood were as efficient as the assays using the cloned target sequence, with the efficiency ranging from 89.67 to 97.07 , and the linearity $\mathrm{R}^{2}$ from 0.992 to 0.999 (Table 1).

It is important to highlight that in all the assays carried out with cultured Candida albicans, cloned qPCR target sequence and spiked blood, the dissociation curves (melt curve) revealed the same temperature of $81.06 \pm 0.19{ }^{\circ} \mathrm{C}$
(Figure 1D). The qPCR had also a high analytical specificity as all other DNA samples from other fungal and bacterial strains tested negative (Figure 2). Similarly, a study using the TaqMan system and the same primers used in the present study did not find cross reactions with the 13 species of Candida tested, or with more than 20 tested species of other fungi and bacteria ${ }^{10}$.

One of the advantages of qPCR is the possibility of an earlier diagnosis (positive qPCR results were reported in patients who subsequently developed candidemia or clinical signs of IC). Moreover, the possibility of monitoring the persistence or resolution of the infection ${ }^{7}$ is also interesting for the patients' follow-up A high sensitivity of qPCR was demonstrated when it was compared to blood cultures in patients with proven/probable or possible $\mathrm{IC}^{7}$.

In a retrospective study, the authors have shown the ability of qPCR in detecting less than $5 \mathrm{CFU} / \mathrm{mL}$ in $23 \%$ of cultured peripheral blood samples from patients with known $\mathrm{IC}^{6}$, and the time required by the molecular technique for 

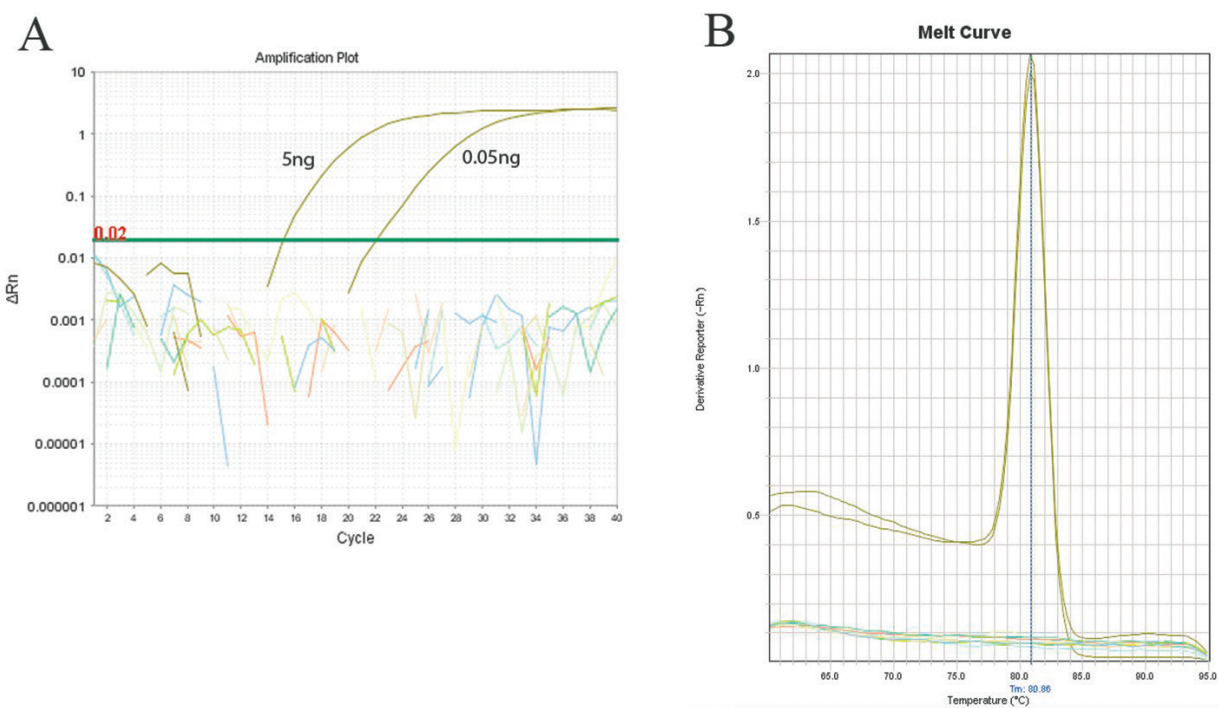

Figure 2 - Specificity: A) qPCR results with 5 and $0.05 \mathrm{ng}$ of $C$. albicans. DNA samples from various microorganisms were tested: C. glabrata, C. parapsilosis, C. tropicalis, C. krusei, C. dubliniensis, Enterococcus faecalis, Pseudomonas aeruginosa, Staphylococcus aureus, Streptococcus agalactiae, Escherichia coli, Rhodotorula sp, Cryptococcus neoformans, Histoplasma capsulatum and Fusarium sp.; B) Dissociation curves for the amplifications observed in A (melting temperature of $80.86{ }^{\circ} \mathrm{C}$ ).

diagnosis is still an advantage when comparing it with cultures, since blood cultures depend on the growing time of yeasts.

Studies with clinical samples have shown that only $53 \%$ of positive cultures had fungal density lower than $1 \mathrm{CFU} / \mathrm{mL}$, in the first culture-positive sample ${ }^{20}$, however, it is necessary to establish a relationship between the amount of CFUs present in the blood sample and the amount of CFUs that have grown in the culture plate. This correlation was demonstrated in a previous study involving experiments with spiked blood, and the authors pointed to a detection limit for C. albicans of $10^{3} \mathrm{CFU} / \mathrm{mL}$ for aerobic and $10^{1}$ to $10^{2} \mathrm{CFU} / \mathrm{mL}$ for anaerobic blood cultures ${ }^{21}$, which could explain the low sensitivity of the culture method in the detection of Candida sp. in blood samples.

Further studies are still necessary to improve and implement the qPCR technique, evaluating its impact on clinical practice. This study has shown that throughout the analyzed parameters it was possible to construct standard qPCR curves with cloned target sequences, reaching a good limit of detection, reproducibility and great specificity. The method used is a prototype strategy based on molecular technology for the development of future assays focused on the detection of $C$. albicans and other Candida sp in human blood to accelerate the identification of the yeast, allowing a rapid and more appropriate clinical intervention.

\section{AUTHORS' CONTRIBUTIONS}

Felipe Delatorre Busser and Vera Lucia Teixeira de Freitas conceptualized, designed the experiments; Felipe
Delatorre Busser, Vivian Caso Coelho and Claudia de Abreu Fonseca carried out molecular assays and the initial analyses; Marta Heloisa Lopes, Gilda Maria Barbaro Del Negro, Marcello Mihailenko Chaves Magri and Maria Aparecida Shikanai-Yasuda contributed to the writing and they critically reviewed the manuscript; Felipe Delatorre Busser, Vivian Caso Coelho and Vera Lucia. Teixeira de Freitas drafted the initial manuscript and reviewed the manuscript. All the authors approved the final manuscript as submitted and agree to be accountable for all aspects of the work.

\section{CONFLICT OF INTERESTS}

The authors have no conflicts of interest to disclose.

\section{FUNDING}

No funding was secured for this study.

\section{FINANCIAL DISCLOSURE}

The authors have no financial relationships relevant to this article to disclose.

\section{REFERENCES}

1. Alam MZ, Alam Q, Jiman-Fatani A, Kamal MA, Abuzenadah AM, Chaudhary AG, et al. Candida identification: a journey from conventional to molecular methods in medical mycology. World J Microbiol Biotechnol. 2014;30:1437-51. 
2. Kullberg BJ, Arendrup MC. Invasive candidiasis. N Engl J Med. 2015;373:1445-563.

3. Pfaller MA, Diekema DJ. Epidemiology of invasive candidiasis: a persistent public health problem. Clin Microbiol Rev. 2007;20:133-63.

4. Girão E, Levin AS, Basso M, Gobara S, Gomes LB, Medeiros EA, et al. Seven-year trend analysis of nosocomial candidemia and antifungal (fluconazole and caspofungin) use in intensive care units at a Brazilian university hospital. Med Mycol. 2008;46:581-8

5. Lau A, Sorrell TC, Chen S, Stanley K, Iredell J, Halliday C. Multiplex tandem PCR: a novel platform for rapid detection and identification of fungal pathogens from blood culture specimens. J Clin Microbiol. 2008;46:3021-7.

6. Anane S, Khalfallah F. Diagnostic biologique des candidoses systémiques: difficultés et perspectives. Pathol Biol (Paris). 2007;55:262-72.

7. Avni T, Leibovici L, Paul M. PCR diagnosis of invasive candidiasis: systematic review and meta-analysis. J Clin Microbiol. 2011;49:665-70.

8. Jones T, Federspiel N, Chibana H, Dungan J, Kalman S, Magee $\mathrm{BB}$, et al. The diploid genome sequence of Candida albicans. Proc Natl Acad Sci USA. 2004;101:7329-34

9. Löeffler J, Hebart H, Schumacher U, Reitze H, Einsele H. Comparison of different methods for extraction of DNA of fungal pathogens from cultures and blood. J Clin Microbiol. 1997;35:3311-2.

10. Guiver M, Levi K, Oppenheim BA. Rapid identification of Candida species by TaqMan PCR. J Clin Pathol. 2001;54:3626.

11. Sambrook J, Fritsch EF, Maniatis T. Molecular cloning: a laboratory manual. $2^{\text {nd }}$ ed. Plainview: Cold Spring Harbor Laboratory; 1989.

12. Riggsby WS, Torres-Bauza LJ, Wills JW, Townes TM. DNA content, kinetic complexity, and the ploidy question in Candida albicans. Mol Cell Biol. 1982;2:853-62.
13. Nguyen MH, Wissel MC, Shields RK, Salomoni MA, Hao B, Press EG, et al. Performance of Candida real-time polymerase chain reaction, $\beta$-D-glucan assay, and blood cultures in the diagnosis of invasive candidiasis. Clin Infect Dis. 2012;54:1240-8.

14. Hsu MC, Chen KW, Lo HJ, Chen YC, Liao MH, Lin YH, et al. Species identification of medically important fungi by use of real-time LightCycler PCR. J Med Microbiol. 2003;52:1071-6.

15. Zhang J, Hung GC, Nagamine K, Li B, Tsai S, Lo SC. Development of Candida-specific Real-Time PCR assays for the detection and identification of eight medically important Candida species. Microbiol Insights. 2016;9:21-8.

16. Schell WA, Benton JL, Smith PB, Poore M, Rouse JL, Boles DJ, et al Evaluation of a digital microfluidic real-time PCR platform to detect DNA of Candida albicans in blood. Eur J Clin Microbiol Infect Dis. 2012;31:2237-45.

17. Maaroufi Y, Ahariz N, Husson M, Crokaert F. Comparison of different methods of isolation of DNA of commonly encountered Candida species and its quantitation by using a real-time PCR-based assay. J Clin Microbiol. 2004;42:3159-63.

18. Schabereiter-Gurtner C, Selitsch B, Rotter ML, Hirschl AM, Willinger B. Development of novel real-time PCR assays for detection and differentiation of eleven medically important Aspergillus and Candida species in clinical specimens. J Clin Microbiol. 2007;45:906-14.

19. Guo Y, Yang JX, Liang GW. A Real-Time PCR assay based on 5.8S rRNA gene (5.8S rDNA) for rapid detection of Candida from whole blood samples. Mycopathologia. 2016;181:405-13.

20. Pfeiffer CD, Samsa GP, Schell WA, Reller LB, Perfect JR, Alexander BD. Quantitation of Candida CFU in initial positive blood cultures. J Clin Microbiol. 2011;49:2879-83.

21. Borst A, Leverstein-Van Hall MA, Verhoef J, Fluit AC. Detection of Candida spp. in blood cultures using nucleic acid sequencebased amplification (NASBA). Diagn Microbiol Infect Dis. 2001;39:155-60. 